\title{
Proliferative and Cytokine Responses by Human Newborn T Cells Stimulated with Staphylococcal Enterotoxin B
}

\author{
ANTHONY HAYWARD AND MARY COSYNS \\ Departme'nt of Pediatrics and Barbara Davis Childhood Diabetes Center, Liniversity of Colorado \\ School of Medicine, Denver, Colorado 80262
}

\begin{abstract}
Staphylococcal enterotoxins are potentially valuable tools for investigating the development of T-cell responses because in experimental animals they can elicit either T-cell activation and proliferation or tolerance. Previous studies indicate that human $T$ cells bearing the CD45RA phenotype (which account for the majority of newborn $T$ cells) respond poorly to stimulation by staphylococcal enterotoxin B (SEB) compared with mature $T$ cells from adult blood. The present studies show that the mean frequency of newborn $T$ cells that proliferated in limiting dilution cultures stimulated by SEB was 1:3135, with a 1SD range of 3153-4191 compared with a mean of $1: 493$ and range of 120-1737 for adult $T$ cells. Neither indomethacin nor the nitric oxide synthesis inhibitor, narginine methyl ester, increased SEB responses by newborn cells, arguing against down-regulation of the newborn response by prostaglandin or nitric oxide. Naive $\left(\mathrm{CD}_{\left.45 \mathrm{RA}^{+}\right) \mathrm{T} \text { cells from adult blood had a responder cell }}\right.$ frequency to SEB similar to that of the newborn cells. IL2 production by newborn cells was delayed compared with adult cells but was equivalent after $3 \mathrm{~d}$ of culture. Production of $\gamma$-interferon and IL- 4 was greater by adult than newborn cells. Our results indicate that a subset of $\mathrm{CD} 45 \mathrm{RA}^{+}$cells that is activated by SEB can mature to make IL-4 or $\gamma$-interferon after 3-5 d. The limiting dilution assay results provide a quantitative basis for proliferation by naive $T$ cells against which responses by $T$ cells from healthy and premature newborns can be compared. ( $\mathrm{Pe}$ diatr Res 35: 293-298, 1994)
\end{abstract}

\section{Abbreviations}

$\mathrm{RCF}$, responder cell frequency

SEB, staphylococcal enterotoxin B

MNC, mononuclear cells

APC, antigen-presenting cells

IFN, interferon

PHA, phytohemagglutinin

LFA, leukocyte functional antigen

T lymphocytes bind antigen through their clonotypic receptors and, under different experimental circumstances, either remain unaffected (1) or become activated or lose the potential for response [or anergized (2)]. The circumstances of activation, and

Received August 18, 1993; accepted October 13, 1993.

Correspondence: Dr. Anthony R. Hayward, B140, University of Colorado School of Medicine, $4200 \mathrm{E}$ 9th Ave., Denver, CO 80262.

Supported by a clinical research grant from the March of Dimes and by NIH Grants HDI 3733 and RR 69 from the NIH Division of Research Resources GCRC Program. in particular the cytokines made by the APC, are likely to be important in determining whether the $T$ cell matures to a memory $\mathrm{T}$ cell or becomes anergized. We have previously found that the human newborns surviving certain severe infections (such as disseminated herpes simplex virus infections) have a low frequency of $T$ cells with specificity for herpes simplex virus in their blood (3). However, the low frequency of antigen-specific $T$ cells in the blood of healthy newborns makes it difficult to determine whether in vivo antigen presentation conditions during an infection might result in some cells becoming anergized. Polyclonal activators such as PHA provided useful early evidence for the capacity of newborn T cells to proliferate and make IL-2 (4), but PHA is an unsatisfactory model activator because proliferation is relatively resistant to depletion of APC. In addition, PHA and concanavalin $A$ both elicit equivalent responses from the naive and memory $T$-cell subsets that are characterized by their CD45 isoforms (5). "Memory" function is generally restricted to the CD45R0 subset of $T$ cells $(5,6)$, and the phenotype switch between the splice variants can be induced in vitro by stimulation with polyclonal activators (7). More than $90 \%$ of human newborn $T$ cells express the $200-\mathrm{kD}$ isoform of CD45-designated CD45RA, which characterizes "naive" cells $(6,8)$. Naive T cells are reported to proliferate less than memory cells (from adults) when activated by antibodies to CD3 (9).

We recently found that the proliferative response of $T$ cells from premature infants to another $\mathrm{T}$ cell ligand, SEB, was reduced compared with full-term controls, although both groups of subjects had equivalent responses to concanavalin $A(10)$. Staphylococcal enterotoxins may be valuable tools for studying the development of $T$ cells because their mechanism of activation of $\mathrm{T}$ cells is relatively well defined (11) and is highly dependent on binding to accessory cells or APC for presentation to T cells $(12,13)$. Information on enterotoxin-stimulated proliferative responses by naive human $T$ cells is limited, and the absence of any estimates of RCF makes it difficult to quantitate differences that might be clinically significant. The studies reported here were undertaken specifically to quantitate the response by newborn cells as representative of a population of naive T cells. SEB was selected as the primary stimulating agent because the molecular structure of this 28-kD molecule is known (14). Each SEB molecule has two binding sites for MHC and one site for the Tcell receptor $\beta$-chains of the $\mathrm{V} \beta 3,12,14,15$, and 17 families (15).

\section{MATERIALS AND METHODS}

Newborn MNC were separated from blood from the placental cord as previously described (16). Blood from healthy adults was centrifuged on a Ficoll-Hypaque gradient (SG 1.077) for $20 \mathrm{~min}$ at $750 \times g$. MNC were recovered from the interface, washed three times in Hanks' balanced salt solution, and resuspended to $10^{6} / \mathrm{mL}$ in RPMI 1640 supplemented with $10 \%$ human serum. 
MNC were depleted of APC where indicated by incubation with $50 \%$ culture supernatant of the HB55 anti-HLA DR hybridoma (ATCC, MD), followed by washing and treatment with antimouse IgG magnetic beads (Advanced Magnetics, Cambridge, MA) and a magnet. CD45R0 cells were depleted with UCHL1, and the CD45RA subset was depleted with $2 \mathrm{H} 4$ as previously described (17).

Conventional cultures. Lymphocytes were cultured in $100-\mu \mathrm{L}$ aliquots in 96-well Corning (cat. no. 25850) plates (Corning, Medfield, MA). Wells were pulsed with $0.25 \mu \mathrm{Ci}$ methyl ${ }^{3} \mathrm{H}$ thymidine (ICN, Costa Mesa, CA, $6.7 \mathrm{Ci} / \mathrm{mmol}$, cat. no. 2406605 ) for $6 \mathrm{~h}$ on the day stated. These cultures were supplemented where indicated with $10^{-5} \mathrm{M}$ indomethacin as described (18). $N$-acetyl-methyl ester (Sigma, St. Louis, MO) was added at $0.2 \mathrm{mM}$ where indicated (19).

Cell cycle analysis. The method of cell cycle analysis was described fully earlier (20). Briefly, control and SEB-stimulated cultures were spun down and resuspended in Hanks' balanced salt solution with FITC-CD3. After $30 \mathrm{~min}$ the cells were washed once, and red cells were lysed with ammonium chloride and fixed in $70 \%$ methanol. These cells were treated with RNase and their DNA labeled with propidium iodide. The $\mathrm{CD}^{+}$(FITClabeled) cells were identified with an EPICS C (Coulter Instruments, Hialeah, FL) and their red (propidium iodide) fluorescence quantitated on a linear scale.

Limiting dilution cultures. We placed two $\times 10^{6}$ blood newborn MNC in $20 \mathrm{~mL}$ of medium in a reservoir and distributed in blocks of 24 replicate wells containing $10^{4}, 5 \times 10^{3}, 2.5 \times 10^{3}$, and $1.25 \times 10^{3}$ blood MNC. Replicates at $0.625 \times 10^{3}$ cells/well were included for adult blood samples. On the 10 th $\mathrm{d}$ of culture, each well was pulsed with $0.25 \mu \mathrm{Ci}$ tritiated thymidine for $6 \mathrm{~h}$, when the plates were frozen to $-20^{\circ} \mathrm{C}$. Plates were harvested on a 96-well harvester and counted on a Betaplate reader (Wallac, Gaithersburg, MD). The data file was reduced in a spreadsheet to calculate the mean plus three times the SD for each set of 24 replicates of the control wells. Wells stimulated with SEB with cpm greater than this mean plus 3SD were designated responder wells. The regression line for log (percentage of nonresponder wells) against cell number per well was determined by $\chi^{2}$ minimalization (21), and the RCF was interpolated at the point that $37 \%$ of cultures would be nonresponders (22).

$T$-cell stimuli. Staphylococcal enterotoxins were purchased from Toxin Technologies (Madison, WI) or Sigma and diluted in sterile water and sterilized by filtration. PHA was purchased from Wellcome Reagents (Research Triangle Park, NC, cat. HA 17 ) and used at a final concentration of $1 \mathrm{mg} / \mathrm{L}$. The CD3 antibody was UCHT 1 , purified from ascites on protein $G$ and used at $0.5 \mathrm{mg} / \mathrm{L}$.

ELISA and Elispot assays. Plastic wells were coated overnight at $4^{\circ} \mathrm{C}$ with monoclonal antibodies, anti- $\gamma$-IFN or anti-IL4 (Genzyme, Cambridge, MA, cat. no. 1598-00 and 1842-01) diluted 1:250 in bicarbonate buffer ( $\mathrm{pH} 8.5)$. Wells were washed with PBS with $0.1 \%$ Tween 20 and blocked with $1 \mathrm{~g} / \mathrm{L}$ gelatin in PBS for $2 \mathrm{~h}$ at $37^{\circ} \mathrm{C}$. For ELISA assays, $100-\mu \mathrm{L}$ volumes of culture supernatant were added to the wells and incubated overnight at $4^{\circ} \mathrm{C}$. The Elispot assays were based on the method of Czerkinsky et al. (23), with $10^{6}$ cells cultured on the plates for $3 \mathrm{~h}$ at $37^{\circ} \mathrm{C}$. The wells (ELISA and Elispot) were then washed and incubated successively with a 1:500 rabbit antibody to the corresponding cytokine (IP500 for $\gamma$-IFN, BL4P for IL-4, Genzyme), biotinylated goat antirabbit IgG (Cappell, Durham, NC, cat. no. 86123711 ) and avidin-conjugated alkaline phosphatase (Cappell, cat. no. 55963). The substrate for ELISA assays was p-nitrophenyl phosphate (Sigma, cat. no. 104), and for Elispot assays it was bromo-chloro-indolyl phosphate at $1.26 \mathrm{~g} / \mathrm{L}$ in AMP buffer. Positive cells in the Elispot were counted by an impartial observer with an inverted microscope and expressed as number per $10^{3}$ cells plated.

\section{RESULTS}

Optimal concentrations of each of the three enterotoxins stimulated equivalent proliferation by adult and newborn $T$ cells (Table 1). Because SEB stimulated the greatest proliferative responses, it was selected for subsequent studies of subset response and cytokine production. The proliferative response to CD3 and enterotoxins was readily inhibited by depleting the responding cells of adherent cells (Table 2). Tables 1 and 2 both show a trend toward lower proliferative responses by newborn compared with adult cells, but this difference did not reach statistical significance. The difference was seen over a range of concentrations of SEB, so it did not appear to result from differences in the dose-response relationship (Fig. 1). Endogenous inhibition of newborn T-cell responses by prostaglandins was unlikely because the addition of $10^{-5} \mathrm{M}$ indomethacin to the cultures did not increase mean thymidine uptake in the stimulated cultures (Table 3 ).

Frequency of $S E B$-responsive $T$ cells. Blood MNC from six newborns and six adults were stimulated under limiting dilution conditions and, in parallel, stained for CD3 to determine the percentage of $T$ cells. The results (Fig. 2) show a straight-line relationship between the percentage of nonresponder wells plotted on a log scale against the cell number per well. The linearity of this relationship is consistent with the notion that only a single cell type limits the response. The RCF on which this plot was based (Table 4) showed a significantly greater frequency in adults than newborns ( $p=0.024$, two-tailed test). The adult samples had a greater percentage of $T$ cells than the newborn samples, but this disproportion was less than that between their RCF. The difference between the adult and newborn samples was seen in limiting dilution cultures that were incubated for 6,8 , or $12 \mathrm{~d}$ (not shown), so it did not result simply from a difference in the kinetics of the proliferative response.

Possible explanations for the reduced RFC of newborn cells included down-regulation by monocyte-derived nitric oxide, a reduced rate of progression through cell cycle, or possibly an intrinsic characteristic of naive cells [which has previously been associated with reduced integrin expression (24)]. The results of cell cycle analysis by propidium iodide staining of $\mathrm{CD}^{+}$cells (Fig. 3) argue against a reduced rate of progression through cell cycle as the mechanism for the reduced RCF of newborn cells. The study shown is one of four with comparable results in which newborn and adult cells reached the $G 2, S$, and $M$ phases of cell cycle at similar rates after stimulation with PHA. Cells in G2, S, and $M$ were detected in the SEB-stimulated adult cultures after

Table 1. Thymidine uptake by staphylococcal enterotoxinstimulated newborn and adult $T$ cells*

\begin{tabular}{lcc} 
& \multicolumn{2}{c}{$\begin{array}{c}\text { Thymidine uptake by } 10^{5} \\
\text { 1ymphocytes }(\mathrm{cpm})\end{array}$} \\
\cline { 2 - 3 } Stimulus & Newborns & Adults \\
\hline None & 5476 & 3344 \\
& $(4730-6350)$ & $(2620-4250)$ \\
Enterotoxin B & 45811 & 51220 \\
& $(37800-55500)$ & $(48700-53880)$ \\
Enterotoxin D & 22243 & 27345 \\
Enterotoxin E & $(17400-28400)$ & $(20090-37230)$ \\
& 13589 & 16691 \\
CD3 antibody & $19070-18030)$ & $(15480-17580)$ \\
& $(17010-23350)$ & 71691 \\
PHA & 38997 & 24860 \\
& $(31883-47700)$ & $(18360-33660)$ \\
\hline
\end{tabular}

* Results are the mean and $1 \mathrm{SD}$ range numbers in parentheses calculated from log-transformed data for five to seven samples per group using optimal concentrations of $0.1 \mathrm{mg} / \mathrm{L}$. Enterotoxin and CD3 stimulation occurred for $5 \mathrm{~d}$, PHA stimulation occurred for $3 \mathrm{~d}$.

† Significantly less than adult CD3 response $(p<0.05)$. 
Table 2. APC requirement for response to polyclonal activation*

\begin{tabular}{|c|c|c|c|c|}
\hline \multirow[b]{2}{*}{ Stimulus } & \multicolumn{2}{|c|}{$\mathrm{Cpm}$ for $10^{5}$ newborn lymphocytes } & \multicolumn{2}{|c|}{$\mathrm{Cpm}$ for $10^{5}$ adult lymphocytes } \\
\hline & Undepleted & APC depleted & Undepleted & APC depleted \\
\hline None & $\begin{array}{c}9680 \\
(8600-10890)\end{array}$ & $\begin{array}{c}8890 \\
(8090-9760)\end{array}$ & $\begin{array}{c}1210 \\
(1030-1420)\end{array}$ & $\begin{array}{r}120 \dagger \\
(80-180)\end{array}$ \\
\hline PHA & $\begin{array}{c}66691 \\
(62720-70910)\end{array}$ & $\begin{array}{c}26695 \dagger \\
(25200-28270)\end{array}$ & $\begin{array}{c}76800 \\
(65980-89400)\end{array}$ & $\begin{array}{c}16900 \dagger \\
(14590-19580)\end{array}$ \\
\hline SEB & $\begin{array}{c}54300 \\
(49800-59260)\end{array}$ & $\begin{array}{c}2940 \dagger \\
(2680-3230)\end{array}$ & $\begin{array}{c}65400 \\
(54600-78300)\end{array}$ & $\begin{array}{c}1750 \dagger \\
(1440-2120)\end{array}$ \\
\hline
\end{tabular}

* MNC were depleted of APC with anti-HLA DR antibody and magnetic beads. PHA stimulation occurred for $3 \mathrm{~d}$, and enterotoxin stimulation occurred for $5 \mathrm{~d}$. Results are the mean and $1 \mathrm{SD}$ range (numbers in parentheses) for log-converted data for four adult and four newborn samples.

† Significantly less than the response by undepleted cells $(p<0.05)$.

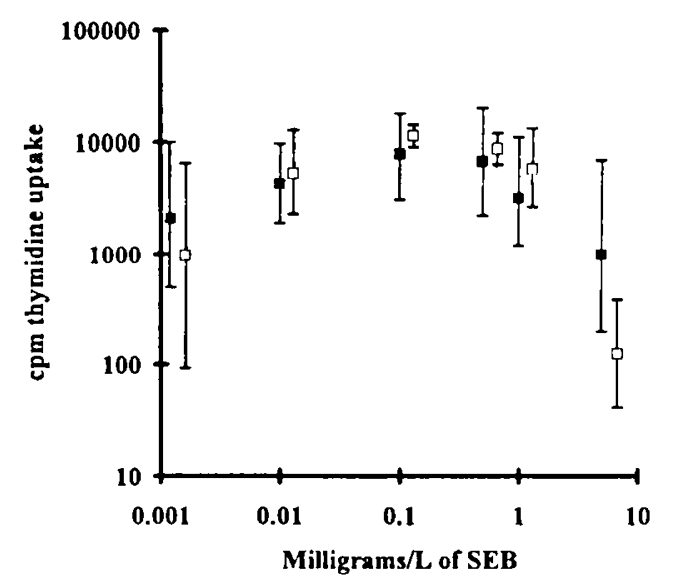

Fig. 1. Dose-response relationship for proliferation by newborn (ם) and adult (口) MNC stimulated for $5 \mathrm{~d}$ with $0.1 \mathrm{mg} / \mathrm{L}$ SEB. Results are the $\log$ mean $\mathrm{cpm} \pm 1 \mathrm{SD}$.

Table 3. Indomethacin and uptake of thymidine by $S E B$-stimulated newborn $M N C^{*}$

\begin{tabular}{lcc}
\hline & \multicolumn{2}{c}{ Cpm per $10^{4}$ cells } \\
\cline { 2 - 3 } \multicolumn{1}{c}{ Stimulus } & Adult & Newborn \\
\hline None & $360(170-520)$ & $660(230-1900)$ \\
SEB & $11700(9600-14200)$ & $8440 \dagger(6540-10900)$ \\
SEB + indomethacin & $10900(7400-13500)$ & $7900(5800-11000)$ \\
\hline
\end{tabular}

* Newborn or adult cells were incubated with $0.1 \mathrm{mg} / \mathrm{L}$ SEB for $5 \mathrm{~d}$. Results are the mean and 1 SD range (numbers in parentheses) for logtransformed data.

$\dagger$ Significantly less than the response by adult cells $(p<0.05)$.

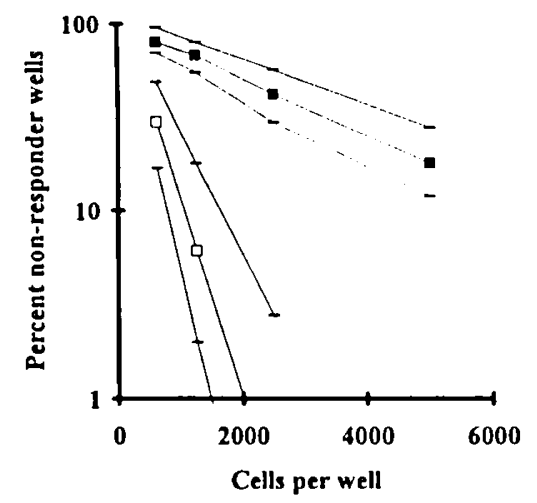

Fig. 2. Frequencies of cells proliferating in SEB-stimulated cultures of newborn ( $\square$ ) and adult $(\square)$ MNC. The ranges shown are +1 SD around the log mean.
Table 4. Phenotype of newborn and adult $M N C$ and frequency of cells responding to $S E B^{*}$

\begin{tabular}{lccccc}
\hline & \multicolumn{2}{c}{ Adult } & & \multicolumn{2}{c}{ Newborn } \\
\cline { 2 - 3 } \cline { 5 - 6 } & $\begin{array}{c}\text { Percentage } \\
\text { CD 3 }^{+}\end{array}$ & RCF (1:x) & & $\begin{array}{c}\text { Percentage } \\
\text { CD3 }^{+}\end{array}$ & RCF (1:x) \\
\hline 74 & 2320 & & 49 & 3213 \\
& 79 & 1621 & & 55 & 3795 \\
& 70 & 153 & & 57 & 4120 \\
& 82 & 122 & 61 & 2990 \\
Mean & 69 & 153 & & 47 & 4320 \\
1 SD range & 77 & 1343 & & 62 & 3560 \\
\hline
\end{tabular}

* Percentage $\mathrm{CD}^{+}$determined by cytofluorograph analysis of $\mathrm{MNC}$ stained with FITC-CD3. RCF determined by limiting dilution of MNC and expressed as $1: x$. The I SD range is calculated from log-transformed values. The difference between adult and newborn response is statistically significant ( $p<0.05$ Mann-Whitney U test).

$4 \mathrm{~d}$ and in the newborn cultures after $5 \mathrm{~d}$, but the slopes of their subsequent accumulation were parallel despite differences in the fraction of responding cells. To test for inhibition of the newborn response by nitric oxide, newborn MNC were SEB stimulated in the presence or absence of $n$-arginine methyl ester. The results (Table 5) show no increase in thymidine uptake or RCF by newborn cells in the presence of n-arginine methyl ester, which argues against a role for endogenous nitric oxide production in limiting SEB responses by newborn cells.

If reduced frequency of cells responding to SEB was an intrinsic property of naive cells, then the adult $C D 45 \mathrm{RA}^{+}$cells response to SEB should resemble that of newborn MNC. To test this idea, we depleted adult MNC of memory T cells with the CD45R0 antibody, UCHL1, and stimulated the remaining naive cells with SEB. Thymidine uptake and RCF by the CD45RA adult cells were similar to the response of unseparated newborn cells (Table 6).

$I L-2, I L-4$, and $\gamma-I F N$ production in SEB-stimulated cultures. After $1 \mathrm{~d}$ of culture the adult cells had more IL-2 in the supernatant than newborn cells; equivalent amounts in all of six newborn and adult samples were found by $d$ 3. Less IL-4 and $\gamma$ IFN were released from newborn compared with adult cells (Table 7). The mean levels shown in the table are for samples that contained detectable amounts of the cytokine. For IL-2 this included all the samples tested. IL-4 was found in three of six newborn samples, and $\gamma$-IFN was found in five of six newborn samples. These cytokines were detected in all the adult samples tested. Some differences existed in the time-to-peak response for IL-4, with newborn samples remaining low for the first $3 \mathrm{~d}$ of culture and rising to about $150 \mathrm{ng} / \mathrm{L}$ on $\mathrm{d} 6$. Adult samples peaked at $250 \mathrm{ng} / \mathrm{L}$ on $\mathrm{d} 6$. The three data points for IL-4 production by newborn cells are too few for statistical comparison with the adult samples. However, if newborn responder and 
human neonate. I. Dysregulation rather than intrinsic abnormality. J Immunol 134:167-171

33. Ehlers S, Smith KA 1991 Differential T cell lymphokine gene expression: the in vitro acquisition of $\mathrm{T}$ cell memory. $\mathrm{J}$ Exp Med 173:25-36

34. Taylor S, Bryson YJ 1985 Impaired production of gamma-interferon by newborn cells in vitro is due to a functionally immature macrophage. $J$ Immunol 134:1493-1497

35. McKenzie SE, Kline J, Douglas SD, Polin RA 1993 Enhancement in vitro of the low interferon-gamma production of leukocytes from human newborn infants. J Leukoc Biol 53:691-696

36. Wu CY, Demeure C, Kiniwa M, Gately M, Delespesse G 1993 IL-12 induces the production of IFN-gamma by neonatal human CD4 T cells. J Immunol 151:1938-1949

37. Lewis DB, Yu CC, Meyer J, English BK, Kahn SJ, Wilson CB 1991 Cellular and molecular mechanisms for reduced interleukin 4 and interferon-gamma production by neonatal T cells. J Clin Invest 87:194-202

\section{Announcement}

\section{Annual Meetings}

The American Pediatric Society, The Society for Pediatric Research, and The Ambulatory Pediatric Association will hold their annual meetings May 2-5, 1994 at the Washington State Convention and Trade Center, Seattle. For further information, contact APS/SPR Association Headquarters, 141 Northwest Point Blvd., P.O. Box 675, Elk Grove Village, IL 60009-0675, phone (708) 427-0205, fax (708) 427-1305 or Ambulatory Pediatric Association, 6728 Old McLean Village, McLean, VA 22101, phone (703) 556-9222, fax (703) 556-8729. 